This item was submitted to Loughborough's Research Repository by the author.

Items in Figshare are protected by copyright, with all rights reserved, unless otherwise indicated.

\title{
Potential and limits of game-based learning
}

\section{PLEASE CITE THE PUBLISHED VERSION}

https://doi.org/10.1504/IJTEL.2020.110047

\section{PUBLISHER}

Inderscience

\section{VERSION}

AM (Accepted Manuscript)

\section{PUBLISHER STATEMENT}

This paper was accepted for publication in the journal International Journal of Technology Enhanced Learning and the definitive published version is available at https://doi.org/10.1504/IJTEL.2020.110047.

\section{LICENCE}

CC BY-NC-ND 4.0

\section{REPOSITORY RECORD}

Greipl, Simon, Korbinian Moeller, and Manuel Ninaus. 2020. "Potential and Limits of Game-based Learning". Loughborough University. https://hdl.handle.net/2134/13621973.v1. 


\section{Potentials and Limits of Game-Based Learning}

Simon Greipl $\mathrm{l}^{\mathrm{a}^{*}}$, K. Moeller $\mathrm{r}^{\mathrm{a}, \mathrm{b}, \mathrm{c}}$ and M. Ninaus $\mathrm{s}^{\mathrm{a}, \mathrm{b}[0000-0002-4664-8430]}$

${ }^{a}$ Leibniz-Institut für Wissensmedien, Tübingen, Germany;

${ }^{b}$ LEAD Graduate School and Research Network, Eberhard Karls University of Tübingen, Tübingen, Germany;

${ }^{c}$ Department of Psychology, Eberhard Karls University Tübingen, Tübingen, Germany

*E-Mail of corresponding author: s.greipl@iwm-tuebingen.de

Keywords: game-based learning; effectiveness; limitations; education; adaption;

resources; balance; 


\section{Potential and Limits of Game-Based Learning}

Because educational games increasingly find their way into the classroom, we aim at outlining potentials but also limitations of game-based learning. First, we compile widely acknowledged benefits, like the ability of learning games to engage and meet the learner's situation. Moreover, we argue that the reduced use of games for learning in higher education does not seem warranted. We propose a three-dimensional framework that highlights the potential of adaptive gamebased learning to catalyse the learning process by addressing cognitive, emotional and social factors of the learner and characteristics of the respective learning environment. We emphasise mandatory considerations like the inability of 'serious games' to replace but complement and enhance traditional educational approaches as well as the misunderstanding that the current generation has a 'native' understanding of technology. With adequate resources, theoretical frameworks, interdisciplinary competencies and clear goals, one can realise effective game-based learning that meets the requirements of modern education.

Keywords: game-based learning; effectiveness; limitations; education; adaption; resources; balance;

\section{Introduction}

The use of games or game-like activities for educational purposes is certainly not a new phenomenon (Prensky, 2007; Djaouti et al., 2011). Undoubtedly, game-based (digital) learning has benefitted from the increasing acceptance of digital entertainment games as mainstream leisure activity (e.g. Lenhart et al., 2008). It is therefore not surprising that digital game-based learning is a research field of continued growing interest as researchers try to harness the engaging and motivational potential of games for educational purposes. However, research in game-based learning is still limited (Snow, 2016).

In the literature, different terms are used to describe activities that make specific use of game-like elements. For instance, the term playful learning primarily subsumes 
games and game-like environments with a focus on the respective learning activities. Gamification, on the other hand, emphasizes the addition of "...game elements to an existing task that may be unengaging, tedious, or boring" (Plass, Homer and Kinzer, 2015, p. 278). As all approaches promote learning in a more or less game-based manner, we will use the terms "game-based learning", "serious games", and "games for learning" interchangeably to refer to this intention.

In the first part of this article, we provide a comprehensive overview on gamebased learning by discussing the paradoxical dissociations of play and higher education as well as reviewing theoretical potentials of game-based learning and its associated results from recent research. We also specifically focus on aspects that have been investigated to a lesser extent so far but are worth taking a closer look at, such as the social character of games.

In the second part, we will specify a new theoretical framework based on above review of the literature: It consists of three basic psychological factors - cognition, emotion, and sociality - for which we argue that they should be addressed primarily and kept in balance to promote learning in game-based approaches.

Finally, we discuss pitfalls and future directions of game-based learning such as the myth of digital nativism and ubiquitous learning, respectively, before ending with a short conclusion.

\section{Overview on game-based learning}

\subsection{Play to learn or learn to play? - The paradox of playing in (higher) education}

The foundation of every game is play. Undeniably, playing is a ubiquitous phenomenon in every child's development and playing usually holds a variety of beneficial 
developmental implications. One might argue that participation in playing a game together with other people (e.g. in collaboration or competition) realizes a special situation that engages and motivates - not only for winning the competition or game but often to advance in some sort of competence or ability. Within such games, individuals sometimes invest intensive physical or cognitive effort and/or very timeconsuming exercises to reach a certain goal (e.g. Krouse et al., 2011; Rüst et al., 2012). Vygotsky (1980) already stated about 40 years ago that playing in childhood enables achievements beyond age appropriateness or usual behaviour, assigning play a crucial role in development.

The usefulness of play in early education (Moyles, 1989) as well as of games for learning in primary education (Hainey et al., 2016) has already been acknowledged. However, learning in playful activities is not merely bound to childhood but often found until higher age. Nevertheless, we find ourselves in the odd situation that with advancements in educational systems learning and playing also becomes gradually detached (Ritterfeld, Cody and Vorderer, 2009). This seems somewhat opposing to aforementioned statements. The important conclusion, though, is that, to the best of our knowledge, there is neither a natural decline in the desire to play nor a decline in any beneficial aspect of playing over lifetime. As such, it remains unclear why playful elements are almost reduced to zero in higher educational contexts.

The muddled picture of this situation is complemented by the introduction of the term "serious game" (Abt, 1970), which is basically setting the purpose of gaming beyond sole entertainment. The term in itself is an oxymoron (see e.g. Djaouti et al., 2011) when one understands playing as, for instance, a playful (but not or not very purposeful) way to spend time. As mentioned before, this seems inaccurate from the 
perspective that the core foundation of gaming is not sole entertainment. That is, the term "serious game" is at least partly redundant.

Importantly, the notion of a causal link between play, games, and learning is by no means new. Starting in the end of the $18^{\text {th }}$ century Friedrich Schiller and JeanJacques Rousseau paved the way to our contemporary understanding of play "as an intrinsically purposeful activity" (Wilkinson, 2016, p. 20). Still, public understanding of games seemingly creates a need for separation that explicitly denotes purposefulness to only some games (i.e., serious games). Again, when we consider this contemporary understanding, development is the ultimate goal and foundation of every play, which is an inherently serious matter. (Serious) Gaming therefore metaphorically and literally struggles against a scientifically and philosophically deprecated conceptualization of playing.

It soon becomes apparent that, if one considers, for instance, a tennis or chess match as a serious game, engaging in gaming activities at least for recreational fun is something people do throughout their entire lifespan. Therefore, the dissociation of playfulness and higher education does not only seem paradox from a social and evolutionary perspective, but also based on cultural and technological development.

The upcoming generation of so-called "digital natives" get more and more used to act in a very playfully enriched digital environment. With simple and cheap accessibility of technology and games, digital playing is available 24/7. Statistics clearly indicate that by far most of today's children between the ages of 12-17 (97\%) play (digital) games on a regular basis (e.g. Lenhart et al., 2008). With respect to entertainment games in the U.S. alone, consumer spent a total of \$30.4 billion in 2016 on video games (ESA, 2017). Of course, one may argue that embedding gaming activities in daily life thwarts later tedious work situations or rote learning in higher 
education and the upcoming generation may have problems adapting. However, we will see later on that this does not seem to be the case.

Nevertheless, there are attempts to bring game-based learning to higher education. One example would be surgical skill acquisition through a virtual reality simulator for shoulder arthroscopy (Gomoll et al., 2007; Rebolledo et al., 2015). Positive impacts of the use of virtual learning environments were shown on other occasions, for instance using the game 'Deal or No Deal' to introduce expected value in a statistics course (Chow, Woodford and Maes, 2011) or the game 'Virtual Singapura' to solve inquiry-based problems related to historical disease epidemics (Kennedy-Clark and Thompson, 2011). There is also evidence that, in comparison to conventional lectures, game-based lessons have beneficial impacts on deep learning and higher-order thinking (Crocco, Offenholley and Hernandez, 2016). Consequently, we cannot come up with a reasonable argument that the potentials of game-based learning may be restricted to a certain age group.

\section{2 (Theoretical) Potentials of game-based learning}

In contrast, there are good and universal arguments to implement games in a broad variety of educational contexts. For instance, game-based learning, gaming elements, and technology were observed to facilitate learning processes and enhance knowledge transfer (Gee, 2003; Prensky, 2007; Connolly et al., 2012; Li and Tsai, 2013; Perrotta et al., 2013; Wouters et al., 2013; e.g. Boyle et al., 2016).

From a theoretical point of view, four core arguments in favour of game-based learning were summarized by Plass and colleagues (2015). First, and mostly referred to, is (i) the motivational capacity of gaming environments. Incentive elements in the form of trophies, stars, or leader boards as well as certain game mechanics are argued to 
stipulate situational interest and are widely used in and known from entertainment games. Closely related is (ii) the player's engagement, which can be facilitated for instance by integrating physical movements or interactions as part of the playing experience. Learner's engagement can also be moderated by (iii) making the game adaptive to meet, for instance, players' capabilities or his/ her specific situation. This for example can result in personalized feedback or scaffolding according to players' achievements and interactions (see e.g. Chen \& Law, 2016; Kao, Chiang, \& Sun, 2017). Lastly, (iv) digital games can create a save environment where it is allowed to make errors, known as graceful failure - alleviating the negative consequences of failing while unfolding the motivational potential of the learning environment.

Implementation of all these aspects is facilitated by integration of latest digital technology. Digital game-based learning opens up new opportunities to create adaptive and secure learning environments as well as the real-time tracking of players' actions and interactions with a digital environment. Furthermore, it was shown recently that games can be used as assessment instruments (Delacruz, Chung and Baker, 2010; Sliney and Murphy, 2011; Shute and Ke, 2012; Lumsden et al., 2016; Ninaus, Kiili, et al., 2017; Shute, Ke and Wang, 2017) and that, for instance, in-game metrics such as point scores etc. can be effective indicators for learning gains (Plass et al., 2013; Kim and Shute, 2015; e.g. Kiili, Moeller and Ninaus, 2018). Consideration of the latter, also known as learning analytics, can provide detailed feedback on strengths and weaknesses or misconceptions of players and thereby allow for customization and personalization of feedback but also learning environments.

This so-called "stealth assessment" provides not only insights about players' performance in formal and informal contexts, it can also be beneficial to players' performance in general by reducing the saliency of examination, pressure, and lastly 
tension (Shute and Ventura, 2013). This seems to result in valid and reliable information about cognitive states but also other personal attributes (e.g. problem solving skill, engagement) allowing targeted feedback (Shute and Moore, 2017). In a well-designed game, assessment takes place while players are fully immersed in playing experiences (Shute, Ke and Wang, 2017). Thus, gained information about individual difficulties, for example, in a specific task or at a specific learning stage may lead the way to tailored support within the curriculum as well as effective mediation and interventions outside the digital game-based learning environment. However, we need to note at this point that online and fine-grained assessment raises some ethical issues that unfortunately need to be discussed elsewhere (Drachsler and Greller, 2016).

To conclude, latest digital technology and games for learning seem to provide an extension to traditional learning settings in terms of immersive and motivating learning experiences with additional evaluative power.

\subsection{Reviewing empirical evidence on game-based learning}

The argument that games constitute an ideal learning medium often gets challenged when looking at the outcomes of recent reviews and meta-analyses (Wouters et al., 2013; Boyle et al., 2016; Hainey et al., 2016). These provide a detailed picture under which circumstances and how games for learning serve as effective learning tools. Apparent problems are the variety of outcomes, variables, and designs the reviewed studies employed. The authors argue that future research would benefit from rigorous experimental studies systematically investigating game elements to identify those who are most effective in promoting engagement and supporting learning. For knowledge acquisition, as the most frequently examined outcome variable, one must be 
aware that the results of most studies seem to point in the same direction of positive effects of game-based learning, but often differ with respect to study characteristics.

As regards games for learning, results are at least equivalent or tend to be superior to those observed for traditional learning environments (Wouters et al., 2013; see Boyle et al., 2016) even though games, designs, and methodologies used are diverse. In other words, the aspects underlying facilitating positive effects on long term knowledge acquisition in games on political science (Nishikawa and Jaeger, 2011) may be profoundly different from the influence of a role playing game that enhances listening, writing, and reading English language (Suh, Kim and Kim, 2010). Nevertheless, in both scenarios the benefit of playing a respective game for learning compared to conventional instruction was feasible. In their recent review, Boyle and colleagues (2016) found that positive influences of games for learning were four times more likely to be found in studies from 2014 than studies published five years earlier. This seems to indicate raising interest in and/or quality of the of games for learning.

Taken together, it can be said that the observed heterogeneity of methodologies within this interdisciplinary field of research has recently led to promote best practices for a more "...systematic process towards the development of a standardized procedure for conducting digital game-based learning effectiveness studies" (All, Nuñez Castellar and Van Looy, 2016, p. 90). Before discussing this in more detail, however, it is worth broadening the scope to non-educational games.

\subsection{Side stages of game-based learning}

Importantly, with respect to outcomes beneficial to learning, one can identify further benefits of games with respect to cognition, skill acquisition, and affect also in noneducational games. First, there is a considerable number of studies indicating that 
playing action video games leads to benefits for attentional and visual perceptual processes (for reviews see Bavelier et al., 2012; Green and Bavelier, 2012). Boot and colleagues (2008), for example, found that playing games that pose high attentional demands (e.g., 'Medal of Honor') lead to faster registration of object changes and better tracking of fast moving objects in perceptual experiments.

Moreover, developing creative and non-standard problem-solving strategies is important in some (learning) games (e.g. Ritterfeld, Cody and Vorderer, 2009). These strategies are then sometimes transferred to other tasks, which was convincingly shown by Hills and colleagues (2008). In their study, a spatial foraging task could either be solved by using a clumpy or scattered search strategy. Depending on their strategy used in the game, participants were observed to reuse their preferred strategy in a subsequent scrabble task to solve an anagram. Interestingly, they stayed with their strategy even when it was suboptimal to cope with the second task. Furthermore, "Tetris", as one of the world's most prominent games, was shown to have a buffering effect on traumatizing memories, compared to an intensifying effect of a verbal pub quiz (Holmes, James, Kilford, \& Deeprose, 2010). A recent study also showed that playing strategy games was positively associated with self-regulation, even when controlling for personality differences (Gabbiadini and Greitemeyer, 2017).

Furthermore, self-regulated learning during play, such as monitoring goal achievement and evaluation of the effectiveness of strategies used (Barab, IngramGoble and Warren, 2009) may be enabled through the allowance of errors and the creation of a safe environment in games (Plass, Homer and Kinzer, 2015). Additionally, this aspect of digital game-based learning environments can be particularly beneficial to learners with high anxiety levels (Kiili and Ketamo, 2017; Yang, Lin and Chen, 2018). 
Another topic worth noting is the acquisition of so-called $21^{\text {st }}$ century skills through games. These skills are widely associated with learning and innovation, comprising abilities such as collaborative work or creativity, complex thinking including so-called metacognition, and skills regarding information and technology (Dondlinger, 2007; Binkley et al., 2012). Boyle and colleagues criticized that, even though games were proposed as promising approaches to support $21^{\text {st }}$ century skills, they seem underrepresented in the literature on the acquisition of these skills. They argued that simple knowledge acquisition "... seems to be a rather pedestrian use of games compared with the speculation about their potential” (Boyle et al., 2016, p. 20), considering that there is promising evidence from, for instance, health and town planning games which were found to support collaborative interactions.

Interestingly, in a recent review on game-based learning and $21^{\text {st }}$ century skills including 29 studies, a third of the empirical work reported medium to large effect sizes (Qian and Clark, 2016). This substantiates the effectiveness of game-based learning to promote $21^{\text {st }}$ century skills. One of these studies reported results about communication, whereas critical thinking was the most frequent used outcome variable. However, $21^{\text {st }}$ century skills are decreasingly treated as a side effect of some game-based learning systems. Instead, as they get acknowledged as key competences, they are increasingly treated as the main goal of the game itself (Echao and Romero, 2017). Irrespective of these promising evidence on game-based learning in general, the question remains: what is the perspective on game-based learning in formal school education?

\subsection{A classroom perspective}

At this point, it may become clear that scientific evidence on game-based learning and gaming in general provides positive evidence for beneficial impacts on learning 
outcomes. However, there also are some more or less apparent problems, like the broad range of game types or genres, the use of differing designs, mechanics, and features to stimulate learners, as well as a, from and educational science point of view, lack of rigorous experimental studies, that in sum impede a coherent conclusion. Therefore, it seems appropriate to focus more specifically on evidence specifically addressing the field of formal education in school. Many of the outcome variables relevant in education were already mentioned above, like cognitive performance or knowledge acquisition. However, to validate the power for assessment and knowledge transfer of game-based learning in educational contexts, effects on academic achievement were often considered the relevant outcome. In this vein, Perrotta and colleagues note the problematic nature of this measure, arguing that referencing academic achievement as an outcome may not be a "...definitive measure against which studies sought to explore impact on learner performance." (2013, p. 14) because it is usually done without further specification of this multi-dimensional variable. Nevertheless, they report five studies that observed positive effects of gaming on academic achievement, whereas another four studies claimed to find no beneficial, but also no detrimental effects.

An extensive practical guide on applying games in the classroom is provided by Becker (2017a). According to her, one should first make use of the content of a given game. In other words, the game should convey knowledge or concepts that have a manifest congruency with curricular contents and needs. While drills and quizzes may be among the first things that come to mind, a particular time period for history teaching or an illustration of concepts like bullying with subsequent discussion also seems feasible (Becker, 2017b). One graspable example Becker offers for games as a facilitator of curricular content is "The Blood Typing Game" (C Nobel Media AB), 
helping students to learn about blood types. In the game, players have to provide a blood bag to a patient after determining his or her blood type.

Another approach of using games in the classroom are counter-examples. In the context of teaching history, the famous game Assassin's Creed II was created under the objective to be historically accurate, with the game being set in Renaissance times.

However, some inaccuracies can nevertheless be found, leaving room for discussing the landmarks where the era is accurately represented and, most of all, where it is not (see e.g. Dow, 2013). Other application scenarios for using games in the classroom comprise Arts, Literature, Music, Physics, or the deployment of a game as a lesson opener or for homework (see Becker, 2017b). For instance, successful implementation of the commercial-of-the-shelf (COTS, mostly referring to commercial games for entertainment) game Portal 2 was reported in a context of high school physics classes (Pittman, 2013), albeit there was no performance benefit or a gain of competencies directly related to playing the game. Civilization III (Squire, 2004) and Minecraft (Schifter, 2013) are popular COTS examples and for the latter beneficial effects have already been reported (Nebel, Schneider and Rey, 2016). Lastly, the meta-analysis by Backlund and Hendrix (2013) reported that 72,5\% percent of the analysed 40 studies found positive results of serious games in formal educational contexts $(17,5 \%$ of the results were neutral; Backlund \& Hendrix, 2013). Half of them addressed elementary school content and mathematics leads the list as the most often touched subject.

Beyond the overall positive picture on the effectiveness of game-based learning in formal education, one should also consider the perspectives teachers and educators as well as learners and/or players themselves have and in how far these are congruent with the direction of the reviewed evidence on learning benefits. Recently, a team of researchers conducted semi-structured interviews with 43 secondary education teachers 
in the Netherlands, all except for one using games in class and six of them using games throughout the year (Huizenga et al., 2017). 41 of them confirmed that games had an engaging effect on students. Furthermore, most of the teachers (38) reported that the games they employed supported learning, specifically mentioning effects on learning the content of the respective subject and collaborative skills, even though competition also seemed to be an important game feature. Only a minority of teachers, however, used games on a daily basis. These results were further substantiated by a large scale survey in the UK completed by 1704 pre- or in-service teachers (Ruggiero, 2013). About half of in-service teachers were using games in the classroom and $75 \%$ of all teachers noted that they want to know more about the use of games in education. The strongest responses on the question how games should be used was "for students with special needs", followed by "as a demonstration of a topic". Additionally, a comparative survey of primary school teachers in Italy and the UK indicated the motivating effect of games and the development of critical thinking and problem solving skills as the main reason to consider the use of games in the classroom (Allsop and Jessel, 2018).

Nevertheless, it has been shown on other occasions that there is broad unawareness of the advantages that come from implementing game-based learning into an instructional environment in many traditionally oriented educators (Bredl and Bösche, 2013). The use of games for learning is spreading fast but often they are only used occasionally and sometimes neglected entirely, which is why we may not conceal that there are several inhibiting factors teachers identify using games for instruction. For instance, Watson and Yang (2016) surveyed 109 primary and secondary school teachers and examined four hindering factors. (i) Many teachers expressed difficulties implementing games effectively, for instance fearing that students may get side-tracked using games. (ii) They mentioned challenges with using technologies, as for example 
the inadequate support for technology or the unavailability of technology to play games on. (iii) Teachers reported limits through the educational system like the pressure of standardized assessments and (iv) they revealed challenges in obtaining relevant games in general. Often, prices of relevant games seemed too high combined with a lack of sufficient funds for purchasing games.

At last, we also wish to consider the view of students on the use of digital games in formal education. Although there are not that many studies on the topic, students generally seem to report positive (Pittman, 2013), but nevertheless mixed evaluations on the usefulness of games. Although students seem to profit from game-based and blended learning in various ways, some students did not seem to see a benefit at all (Camilleri \& Camilleri, 2017). In particular, perceived benefits seemed to depend on the ease of use, learning potential and personal experience with games in general (Bourgonjon et al., 2010).

Importantly, however, even though the focus often is on gains in academic achievement or other performance measures when it comes to effects of games in education, it may be worth to look at effects beyond purely performance-oriented aspects as well.

\subsection{Sociality in (serious) games}

Many mechanics used in game-based learning originate from commercial entertainment games. One of the developments of the last 20 years is that digital games became more and more a social activity, like the word "massively multiplayer" suggests in the acronym MMORPG (Massively Multiplayer Online Role-Playing Game). In fact, social interaction within a game can make up a large part of its motivational essence, meaning the desire to return to play or its "stickiness" (Plass, Homer and Kinzer, 2015). 
Although Plass and colleagues argue that the social aspect of gaming is tightly linked to a cultural aspect, they eventually distinguish the two concepts because there are games that promote either one or the other. About ten years ago, almost 12 million people played the MMORPG World of Warcraft via the internet (Peckham, 2013). Today, around 250 million people play the battle royale game Fortnite by March 2019 (Insider, 2019). If anyone is still stereotyping gamers to be socially isolated, this is surely a deprecated perspective. Gaming has become mainstream (Lenhart et al., 2008) and most of currently released commercial games have, depending on their genre, some game mode that has social character (for instance an (online) multiplayer mode, or at least features like leader boards, chatrooms or forums).

As reported earlier, learning - and in turn play - is essentially socially constructed and motivated (e.g. Bandura, 2002). Therefore, we have to take account of the fact that "the process of learning is located at the interface of people's biography and the sociocultural milieu in which they live..." (Jarvis, 1992, p. 17), which calls for a closer look at the social character of games in general and games for learning in particular. Consequently, Illeris (2007) describes interaction between the individual and the environment as part of the learning process and "...the fact that the environment in connection with learning is quite overwhelmingly social and societal in nature." (Illeris, 2007, p. 25). As such, game designers as well as teachers thinking about implementing games in their lesson plan should carefully consider the social character of the respective game. For instance, social interaction within games was observed to have an impact on self-perception and beliefs about one's own ability (Plass, Homer and Kinzer, 2015).

Generally speaking, the formation of identity already begins with the group membership (Tajfel and Turner, 1979). Being part of a group and establishing 
connections to others leads to feelings of relatedness (Self-Determination-Theory; Ryan \& Deci, 2000). Additionally, feedback from other players may significantly influence the players' feelings of worthiness and may alter positions and identity within the group (Plass, Homer and Kinzer, 2015). Accordingly, important factors like engagement or the wish to play again are partly driven by the sense of being connected to others (Ryan, Rigby and Przybylski, 2006) and therefore grounded in social interactions. Furthermore, self-efficacy and, finally, learning performance may notably be affected by such social interactions (Plass, Homer and Kinzer, 2015). Social contexts like a community of practice (i.e., a group coming together for a shared domain of human endeavour, which can be learning itself), were found to have beneficial effects on learning (e.g., Wenger, 2008). Importantly, however, benefits of social aspects of gaming do not only stem from playing in groups. Even in single player settings, the use of leader boards puts one's own performance into relation to others and can have a moderating effect on players' motivation (e.g. Nicholson, 2013). In fact, social pressure elicited through the comparison with others may determine how frequent and effortful players engage in the game in the future (Plass, Homer and Kinzer, 2015).

Furthermore, the use of mobile technology opens new ways of using social competitive or collaborative game play for learning. However, the competitive character of a game may lose its motivational potential, or even be detrimental to the motivation of the player if it is set up as nothing more than an extrinsic reward. Importantly though, modern technology may provide a workaround here. As devices can be interconnected easily, playing against each other is not a big technical obstacle anymore. A digital learning environment may implement its competitive character, even when the competition is only there for its own sake, in a way to retain its motivating character but losing some of its pressuring characteristics. For example, in a one against one 
competition, the game system can first randomly assign pairings, but leave both players anonymously at least for the time playing. This way, the learning situation would benefit both from the motivation of playing against a real person - someone I know in this room - and from bypassing maybe some social preoccupations or resentments from existing classmate relationships.

Motivation in competitive settings mostly relies on player versus player interactions (Cagiltay, Ozcelik and Ozcelik, 2015). In contrast, collaboration needs the players of a group to act in concert (e.g. Hämäläinen and Oksanen, 2012; Yang, 2012). This is reflected in Banduras (2002) concept of collective agency which is important for motivation and goal orientation. Consequently, with goal-directed behaviour being related to learning, both competition and collaboration can affect learning performance (Burguillo, 2010).

Up to date, however, there is no consensus on the theoretical framework of effective implementation of collaboration in game design. Additionally, research remains ambiguous on how both collaboration and competition influence learning processes (Sanchez, 2017). In particular, Sanchez argued that "from an educational point of view, it might not be relevant to oppose competition and collaboration but merely to consider that they are two interdependent and inseparable core dimensions" (2017, p. 167). Generally speaking, the use of technology for collaboration seems to facilitate achievement, cognitive development, and positive attitudes more than competition (Johnson and Johnson, 1996).

Collaboration is also thought to facilitative learning of $21^{\text {st }}$ century skills, showing one of the largest effect sizes compared to other game elements in a recent meta-analysis (Qian and Clark, 2016). However, competition did, too. ter Vrugte and colleagues (2015) found no differences in game-based learning outcomes between 
competition and collaboration, but did find an interaction with students' ability level in the sense that competition was detrimental to collaborative learning for students with low ability. It may be worth noting that collaboration usually has positive effects on attitudes, but not necessarily on performance (Ke and Grabowski, 2007).

Lastly, Sanchez (2017) pleads for games to be treated as coopetitive systems, because collaboration and competition are intrinsically connected but different dimensions linked to the learning process. In this context, a recent example on how to integrate competition and collaboration in a game for learning, Kiili and colleagues (2018) employed a country-wide math game competition. During a three-week period, Finnish fourth and fifth graders participated in a math game competition relying on intra-classroom cooperation and inter-classroom competition. Through the game, participants significantly improved their rational number knowledge and in-game metrics were a valid predictor of students' rational number knowledge. Importantly, students were very engaged in the competition and results further indicated that intrinsically motivating factors, such as enjoyment and perceived learning gains predicted students' willingness to participate in math game competitions again (Kiili et al., 2018). This study provides first empirical support that educational game competitions might be an effective and engaging instructional approach. This leads us to conclude that the balance and interdependency of competitive and collaborative elements in a game seems to be the key aspect of game design to be reflected on in order to simultaneously engage and educate its players.

\section{Multiple equilibria - a balancing act}

\subsection{Cognitive, emotional, and social factors of game-based learning}

Overall, games with educational purposes make up a large part of the scientific research 
field of game-based learning (e.g., Boyle et al., 2016). From our review above, it became clear that games offer potentially powerful features to stimulate learning on different levels. As a holistic approach to learning, cognitive, emotional, and social factors reflect the constituting pillars of game-based learning experiences. Therefore, in the following, we will provide a short overview of how these factors can be addressed by games and how they are interrelated.

Cognitive factors:

Besides motivation, engagement, and affect, cognitive aspects like learning outcomes, visual perceptual ability or attention are the most widely evaluated aspects of gamebased learning (e.g., Boyle et al., 2016). One major advantage of digital games is the ability to adapt to the player's needs on psychological dimensions such as cognition. In an optimal scenario, a digital learning environment would be able to measure subjective cognitive load of players and adapt learning tasks in a way to achieve a balance between tasks being neither too easy nor too difficult. Both extremes may lead to either boredom or overstraining, respectively, and ultimately to quitting the game and thereby the learning experience (Plass, Homer and Kinzer, 2015).

On the cognitive level this is usually obtained by, for instance, adapting the complexity of the task to correspond to capabilities and advances of the player. Balance between cognitive demands of the task at hand and individual capability level is often described as the state of flow (Csikszentmihalyi, 1990) and references the original concept of Vygotzky's zone of proximal development (1980). Reaching a state of flow has been treated as a framework and key goal of game design (Kiili et al., 2014; Tahir and Wang, 2017) as well as an auspicious strength of successful games in general. In this context, the dependency between arousal or stimulation, respectively, and 
performance was first described at the beginning of the $20^{\text {th }}$ century by the so-called Yerkes-Dodson-Law (1908). It postulated an inverted U-shaped relation between performance and arousal. That is, learners' maximum performance should be achieved on a medium level of arousal whereas performance decreases when arousal becomes too low or too high. However, equilibration of players' cognitive load by task demands (i.e., arousal) is only one of the features applied to keep players engaged and to facilitate learning.

\section{Emotional factors:}

A very important, but ironically sometimes largely neglected, factor of game design is affect and emotion, respectively (Wilkinson, 2013). From a user experience perspective, emotions can be treated as "the heart" of the game, making them a more memorisable experience (Schell, 2015). Importantly, the intriguing perspective in educational game design is that emotions have a mutual influence on attention, memory, and cognition (Moreno, 2006; Izard, 2009; Plass and Kaplan, 2016) and therefore play a crucial role in learning. For instance, in game-based learning, frustration can entail a decrease in motivation towards learning (Craig et al., 2004). Generally, game-based learning itself has been propagated as a utilization of game features to encourage, amongst other aspects, motivation and positive affect in learning activities (Gee, 2003; Kapp, 2012). Prevalence of positive affect is indeed useful, but one also needs to consider that failing, and associated negative emotions, are inseparably tied to learning. As such, it would be a fallacy to neglect these just because of the anticipation of undesirable effects. In particular, because it is known that it is the degree of arousal rather than its valence which modulates memory formation (Nielson and Powless, 2007). Therefore, such negative experiences may not necessarily be detrimental for players in terms of 
engagement, motivation (Petralito et al., 2017), or even learning outcome (D’Mello and Graesser, 2014). Instead, they may rather be beneficially integrated in the game by allowing for productive and graceful failures (Kapur, 2008; Plass, Homer and Kinzer, 2015).

In this context, productive failure refers to the reversion of the classical sequence to first instruct students about the matter to be learned and then solve related problems individually. By trying to find solutions to an unknown problem prior to any instructions, students very likely run into errors. While this may not produce optimal short term performance, students seem to benefit from subsequent instructions and actually increase their long term performance by, amongst others, better integration of prior knowledge (Kapur and Bielaczyc, 2012).

The term graceful failing though captures the erroneous aspect of learning from a motivational rather than from a mere performance perspective. By allowing to face failure with serenity in games one may in turn facilitate risk taking and exploration in the game (Hoffman and Nadelson, 2010). Nevertheless, studies focussing on emotions and affect in learning are rather concerned with methods and game elements that specifically induce emotions. The effect of positive emotions has been shown to be beneficial on learning outcomes (e.g., Um, Plass, Hayward, \& Homer, 2012). There is, however, the notion that also confusion may lead to enhanced learning (D’Mello and Graesser, 2014) and that different affective states seem to have considerable influences on players' intrinsic motivation (Heidig, Müller and Reichelt, 2015). The influence of less positive aspects or even negative emotions, and, most importantly, the interaction of positive and negative emotions on learning, have hardly been investigated so far.

Importantly, however, it needs to be noted that evoked emotions can exceed the self-regulating capabilities of the player, resulting in an emotional overload and 
overstimulation, or can lead the attention away from the learning object (Plass and Kaplan, 2016). Accordingly, emotional stimulation with certain game elements might be understood in a similar way as the above described inverted U-shape relation between (emotional) arousal and performance.

\section{Social factors:}

The previous section already highlighted the social nature of games. On he one hand, the pure situatedness of a learning process places a social core factor, for example simply being together with friends or students in a (class)room, being connected online or playing alone (at school, home etc.). On the other hand, comparison between players in form of leader boards for instance, represent indirect social interactions. Moreover, games often implement interaction with other players and/or the game itself in form of competitional and collaborative game elements. A wide resume would be that the continuum of social stimulation in a game, this means playing a game, offline and alone at home versus playing competitively together with a lot of people, can have considerable impact on learning performance.

\section{Interrelation and dynamics:}

Skill dependent benefits for learners through either collaboration or competition (ter Vrugte et al., 2015) as well as the positive impact of epistemic interactions on learning through coopetition (Sanchez, 2017) already stress the interrelatedness of cognitive and social aspects. Moreover, we can also assume that emotions modulate cognitions (Izard, 2009) and even that they are "inherently interconnected" (Plass and Kaplan, 2016, p. 134). The same holds true for the connection between emotions and sociality, e.g. when players get pushed or demotivated when they are on top or on bottom of a leader board, respectively (Nicholson, 2013). Because all of these factors (i.e., cognition, emotion, 
and sociality) are interrelated they might provide bolstering effects for a lack of resources in one factor to get closer to an optimal state of learning. However, we do not want to claim that a possibly diminished resource can be compensated by another factor.

In sum, cognition, emotions, and sociality are interrelated and dynamic factors of game-based learning. By utilizing flexible game design and adaptive core game structures these factors need to be kept in balance dependent on the player's situation and the learning goal. The following aims at specifying the aforementioned balancing act by synthesizing it into an equilibration framework and illustrating it with examples from the literature.

\subsection{The equilibration framework}

Considering the potential flexibility and adaptivity of games, we may think of games for learning as tools capable of much more than only synthesizing or repacking a specific content to be learned. They may indeed create an actual learning experience that conveys a content in a more holistic and individually tailored way. Digital gamebased learning environments provide a framework in which cognitive, emotional, as well as social factors can be addressed to foster optimal learning experiences. In view of what has been discussed in previous paragraphs and the Integrated Cognitive Affective Model of Learning with Multimedia (ICALM; Plass and Kaplan, 2016), it becomes clear that cognition and emotions are crucial components in learning. In the special case of learning with games, learning experiences might be further enhanced by considering social features (see for instance social engagement in Plass, Homer, \& Kinzer, 2015). Consideration of a social factor captures the process of learning with games more holistically, because social characteristics play a major role in learning and development in general and in today's game-design in particular (Plass, O'Keefe, et al., 2013). 
As such, cognition, emotion and sociality in game-based learning might be understood as resources or predispositions for learning a player is equipped with on the one hand and cognitive, emotional, and social features of a game environment on the other hand. Together they constitute a profile of resources individually modulated by stable and flexible factors. When speaking about "meeting the player in his or her situation", situational factors comprise the player's personal predispositions as well as the actual situational or external influences in a learning situation or game, respectively. The former includes aspects like personality traits (e.g., preferences for certain game elements, Tondello et al., 2016), cognitive capacities (e.g. working memory capacity Sanchez and Wiley, 2006) and further individual dispositions relevant in the context of learning (e.g., self-efficacy or acceptance of game-based learning, Ninaus, Moeller, et al., 2017).

The latter refers to the learning-situation itself that, for instance, modulates the envisaged learning goal, motivation and engagement of the learner and in turn his or her baseline approach or general interest in the learning situation or content. As human minds develop in social situations and learning is therefore per se "situated" (Lave and Wenger, 1991)

In the vein of ideal resource management, the dependency between capabilities and task demands has been described previously. Originally investigated in rats, the Yerkes-Dodson-Law (Yerkes and Dodson, 1908), as introduced above, is one of the first empirical models describing the relationship between arousal and performance. Often illustrated by an inverted U-shaped curve reflecting that task performance will decline when the optimal arousal is undercut or exceeded. Building upon these theories and the possibilities of digital game environments, we propose that emotional, cognitive, and social (see Figure 1A, respectively) predispositions or resources of an 
individual as well as cognitive, emotional, and social features of a game need to be carefully balanced to achieve an optimal learning situation. Although cognition, emotion, and sociality are usually interrelated, a separate perspective on how balancing is achieved or missed, respectively, might be more illustrative.

Cognitive resources are limited and may thus be overstressed by, for instance, making the task too complex, which might lead to cognitive overload due to limited working memory capacities, for instance (see e.g. Kirschner, Kirschner and Paas, 2009). Although it is sometimes argued that (time) pressure can be facilitative in terms of productivity, under certain circumstances, this usually comes at the expense of quality (Moore and Tenney, 2012). Considering aforementioned theories such as the YerkesDodson-Law or the idea of a zone of proximal development (Vygotsky,1980), we would assume that very simple and likewise very complex tasks eventually lead to boredom/frustration as well as demotivation and may therefore interfere be detrimental to learning. In line with this argument Engeser and Rheinberg (2008) manipulated difficulty from low to high in the popular game Pac-Man and found that this lead to a moderate quadratic relationship between demands and flow experience. This means flow was highest for participants at medium levels of difficulty when there was a balance between demands and individual resources to meet these, but lower when task demands were either too low or high.

Emotional resources can likewise be overstrained by evoking too much emotional arousal. Analogously, however, understraining would cause a need for further arousal through a lack of stimulation by the environment (Krannich et al., 2019). In this sense, (emotional) over- or underchallenge in school seems to be an antecedent of anxiety or boredom (see e.g. Daschmann, Goetz and Stupnisky, 2011), which - in turn often leads to avoidance (Pekrun et al., 2014). For instance, in the context of 
mathematics lessons, momentary boredom was found to be negatively related to competence appraisals (Ahmed et al., 2010). A direct manipulation of emotional impact can for instance be realized using specific design elements for presenting information in a game. For instance, in a study on multimedia learning about the immune system, Plass and Kaplan, (2016) found that manipulating the shape of the presented figures (e.g. face-like round) led to significant induction of positive emotions.

Sociality and social resources - as a core component of learning - can be addressed and manipulated in numerous ways (e.g. Harteveld and Bekebrede, 2011). Collaboration and competition alone have considerable influences on learning. For example, collaboration was observed to have a positive effect on learning in belowaverage performing students when there is no competition (ter Vrugte et al., 2015). Moreover, implementation of both competition and collaboration in games as coopetitive systems was found to result in epistemic interactions, and finally learning from playing the game (Sanchez, 2017).

Overall, the social human nature places various social needs and drives (e.g. Tajfel and Turner, 1979; Ryan and Deci, 2000) that can be accommodated by games and eventually act as resources. Which situation is the most beneficial one lastly depends on the possibilities of the game on the one hand, and the disposition, socialisation, and preferences of the player on the other hand. A desirable game-design would, for instance, allow the player to decide whether to play by oneself, competitively, collaboratively or coopetitively. In a similar manner, many commercially available entertainment-games offer the player a single-player, multi-player or cooperative playing mode (e.g., Mario Kart, Grand Theft Auto 5, Battlefield V).

Based on these considerations, we argue that the factors of cognition, emotion, and sociality contribute reciprocally to either a catalysation or an interference of the 
learning process, depending on the quality and flexibility of adaption of the game. As resources and predispositions in these three dimensions vary considerably between learners/players, their proper balancing seems to be the immanent key goal but also potential of game-based learning.

Reflecting the inverted U-shaped association described by the Yerkes-Dodson law, the illustration of our framework is a combination of the three factors - cognition, emotion, and sociality - which can geometrically be described as a hyperboloid (see Figure 1B). The centre - the "belt area" with the smallest radius - represents the zone with the highest potential for catalysing the learning process. This illustration is visually, but not conceptually rigid, meaning that the optimal adaption always takes into account the three basic factors, but the most appropriate profile to approach the optimal learning centre is highly individual. 
A

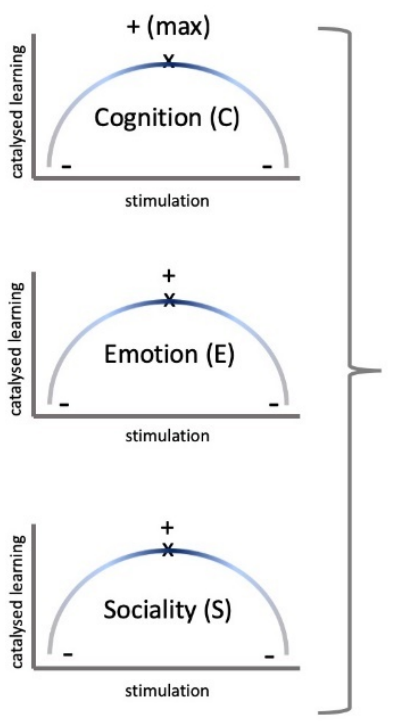

B

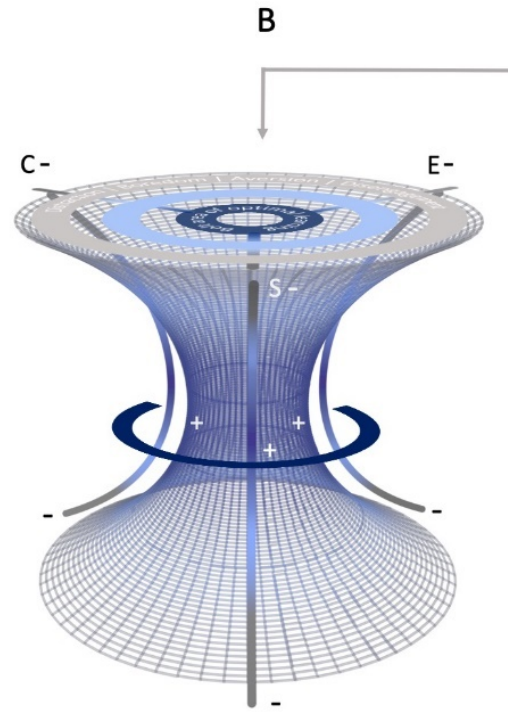

C

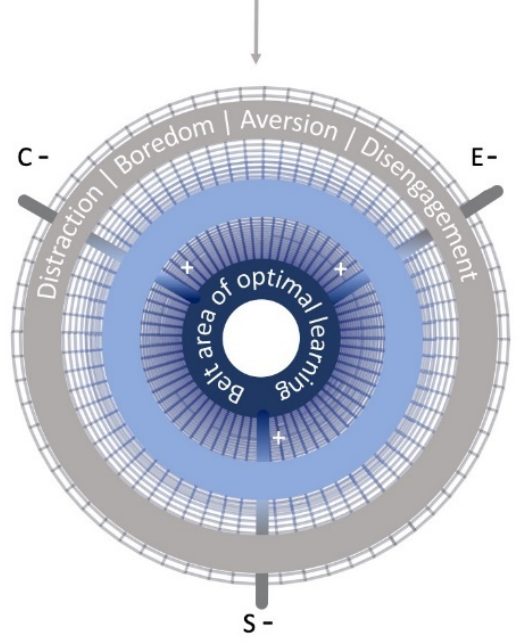

Figure 1: A) depicts the inverted u-shaped association of the factors emotion, cognition and sociality with learning. The hyperboloid (B) represents the fusion of the three graphs/factors. Its centre - the "belt area" - represents the point of optimally catalysing the learning process by ideally engaging the learner's resources. Towards the extremes of the two "funnels", resources get gradually over- or understrained and learning may be reduced. The top view $(\mathrm{C})$ schematically illustrates the interdependence of the factors.

\section{Pitfalls and future perspectives}

\subsection{High potential to fail}

It would be easy and not very useful to plead for the many promising aspects mentioned in this article or in the literature more generally. However, our proposed framework emphasizes the need for balance between players' dispositions and games' possibilities as well as the balance between each of the three envisaged factors. While there are feasible opportunities to create focussed and sustainable learning experiences, represented by the centre (the "belt-area") of our illustration, there is also potential for miss-stimulation or even deterrence with respect to the game and/or the learning content. These comparably large "divergence areas" accentuate the potential for sub- 
optimal game design. Consequently, keeping the game balanced on many factors according to players' situation inherits several possibilities to create negative consequences for learning outcomes and players' motivation. The very simple example for maladaptation or imbalance is a game making the task too easy or too difficult for the player. A different pitfall might be the use of too many game elements for learners with low cognitive resources resulting in the so-called seductive details effect (Sanchez and Wiley, 2006; for a review see Rey, 2012), as they might "over-stimulate" players. Therefore, by enriching a task with game-based elements, trade-offs may be necessary (Greipl et al., 2019), which reflect so-called design problems (addressed more exhaustively elsewhere, see e.g., Schell, 2015).

An illustrative special case of flawed overall game design is the so-called chocolate broccoli problem (Klopfer, Osterweil and Salen, 2009, p. 18). It refers to the risk that with reduced novelty, the attractiveness of a game declines rapidly in case the game is only a superficial repack of an otherwise undesirable content (e.g. Breuer, 2017). Boredom or even reactance are possible consequences in case learners realize that they became a victim of false advertising because game-developers or teachers were covertly trying to sweeten the pill. This may be the result of poor planning, uninspired design or the desire for fast results. Especially younger kids are prone to back away from games that are labelled as educational (Klopfer, Osterweil and Salen, 2009).

Nevertheless, empirical evidence showed that quick and dirty solutions contradict the intentions of game-based learning (Walldén and Soronen, 2004) and reduced acceptance of a game may possibly hinder the learning progress.

While critical voices may at this point think of deterrent pictures of distracted and left alone students in a classroom, we want to emphasize that games for learning 
and game-based learning is thought to be a supplement rather than a substitute for formal education. Games for learning can be tools for teachers and instructors to motivate and engage learners beyond capabilities of traditional learning environments. Some benefits arise primarily due to potentially improved learning outcomes, but secondarily through having more time and resources to be spent on after initial set up and instructions. For instance, teachers may improve relationships to students or provide individual support given the additional information some games provide. This way, a game can never be a standalone or even autonomic concept for teaching. Additionally, most current games are created for a single or a limited set of educational purposes and are therefore restricted to them. For instance, in a simulation game for sustainability, the game may not provide exhaustive information or some information stays unnoticed by learners which makes the combination with other teaching forms (e.g. group discussions) necessary (Pohl, Rester and Judmaier, 2009).

Finally, one needs to consider some cultural or developmental aspects of students that represent dispositional obstacles. We may be right to recognize an advantage when our children grow up with technology and learning how to use them from early ages on. But we are likely mistaken when we speak of "digital natives" and refer to persons that holistically comprehend computer technology because they simply have been exposed to it their entire lives. Empirical evidence shows that this is not even the case when it comes to mere usage of standard (input) devices. For instance, Pittman (2013) noticed that his students lacked basic computer control skills, like keyboarding and mouse handling (2013). He pointed out that the inexperience with computer games in general accounted for the biggest setbacks when teaching physics with the game Portal 2. In the first-person perspective, some students had serious problems getting a sense of their position within virtual space, making navigation in a room a hard task. 
There is also no reason to believe that the generation of digital native somehow learns differently from previous ones (Margaryan, Littlejohn and Vojt, 2011). And the fact that "simply being connected does not make one literate" (Becker, 2017a, p. 219) basically reminds us that how people use information is still more relevant than how many times they access it (Bulger, Mayer and Metzger, 2014).

\subsection{Future directions}

Empirical research in its current early stages primarily focussed on the question whether game-based learning works rather generally. With respect to gamification, this led to a variety of gamified systems and effect measures indicating face-validity of such systems (Hamari, Koivisto and Sarsa, 2014). Now, we can see a shift away from mere effectiveness-studies towards more theory grounded research. However, there still is a need for that because it is the integration in overarching theoretical frameworks which provides the opportunity to form a "joint knowledge structure” (Nacke and Deterding, 2017, p. 2). Theories reconcile divergent findings, point to future hypotheses, and give hints to achieve successful transfer effects into practice (Deterding, 2014).

We already stated earlier, that the heterogeneity of research methodologies and designs seems to blur the picture when evaluating the effectiveness of game-based learning. Therefore, some research teams have already begun to resolve this issue by demonstrating best practice approaches to evaluate the effectiveness of game-based learning systems. For instance, All and colleagues argued for room for improvement on an intervention and a methods dimension amongst others (2016). The former includes aspects such as explicitly manipulating which game features are omitted or enabled during an intervention in the experimental and control group, respectively. On the methods dimension, they mention several methodological points from the necessity of 
pretesting materials, the necessity of a control group, and a minimum time lag of 2 weeks for a follow-up test. These represent a start in systematically operationalizing the effectiveness of game-based learning in a way done in educational sciences more broadly and with respect to cognitive, emotional, and social factors in game-based learning research in particular.

Moreover, some of the variety of outcome measures in game-based learning research may come from the two different approaches on how games are implemented in educational contexts. Usually, one of them is adopted by advocates of game-based learning (Klopfer, Osterweil and Salen, 2009). It refers to commercial-of-the-shelf games as representative for today's $21^{\text {st }}$ century life and describes the capacity to engage learners to be superior to school. The other approach aims at promoting the use of games for learning in more traditional academic contents. The latter group though embraces school and almost eschews real gaming, whereas the former tends to abandon conventional methods (Klopfer, Osterweil and Salen, 2009). While for the use of COTS games in education instructional guidelines can already be found (Becker, 2017a), developing an educational game first leads to a challenge in terms of interdisciplinarity. To integrate information technology and, for instance, psychological and pedagogical expertise, one needs a pool of competencies and resources that must conjointly focus on a clear learning goal to be put into practice.

Even when a game for learning is already developed and available, there are impediments that come from the institutional side, like lack of resources, administrative support or overall unsupportive organizational climate with respect to information and communication technology (ICT) to evaluate this educational game in the field. In this context, is the constructivist approach is an interesting attempt that emphasizes the students' point of view instead of using highly trained experts to develop a game. As 
such, students themselves build up a viable learning game for their peers while simultaneously gaining skills in, for instance, mathematics, science, or computer programming (Kafai and Burke, 2015). When we try to anticipate the future of digital game-based learning, technological advances may prospect some directions and might even have one of the most pronounced influences. The last 15 years made available technical devices smart, small, powerful, and most of all, portable. By now, mobile gaming (e.g., on smartphones and tablets), with already about $40 \%$ of the gaming market, makes up a continuously growing percentage (Newzoo, 2017). This trend transfers to gaming in general which then also results in a shift towards mobile gamebased learning and so-called ubiquitous learning. The latter refers to putting the learners in different physical learning contexts, making the learning experience dynamic and flexible (Park, 2011; Giannakas et al., 2018). For instance, augmented reality uses the device's camera to enhance and underpin real-world content - opportunities that were not possible only a few years ago. This opens intriguing educational opportunities, for example, on a spatio-temporal dimension. Learners may profit from an enriched, individual and meaningful experience "...by placing them in an authentic learning context anywhere and anytime" (Giannakas et al., 2018, p. 349). At the same time educational challenges and unique affordances like portability, social interactivity, context sensitivity, connectivity, and individuality need to be considered (Klopfer and Squire, 2008). On the one hand, potent (mobile) technology and hardware proceeds to be available for practically everybody and everywhere and the start of "gaming on demand", providing high end gaming on comparably cheap hardware as a service, formal education may have to come up with a way to create a nexus between technology and education. Not only because technology and digital learning environments host powerful mechanisms for learning, but also because the use and 
knowledge about technology itself constitutes a $21^{\text {st }}$ century educational and societal necessity.

\section{Conclusion}

We may tentatively infer that games and their growing significance for the global market as well as the fact that they are mainstream by now may likewise give impulses for the significance of games for learning. Capable - but at the same time affordable hardware in combination with high-performance networking infrastructures may open new possibilities for digitally enriched learning environments as effective extensions to existing educational concepts. But how do we use the full potential of game-based learning?

From the perspective of technological progress, it will be essential that nonprofit sectors such as education, find a way to keep up with the still fast advances. To do so, one needs to focus on a clear learning goal, ground any development in solid theoretical frameworks, and try to implement and adapt to sophisticated industry standard game design. Moreover, as technology gets more seamlessly implemented in our everyday lives, curricular extensions with respect to digitization will become mandatory to stay - from an educational perspective - more life-oriented and everyday life like. Additionally, this means that schools have an obligation to provide students access to and knowledge about technology in general. From a scientific perspective, the theoretical aspects above all strongly recommend the use of games for learning, while practical evidence provides promising, but occasionally mixed results. Due to a lack of rigorous long-term investigations, we are still waiting for more compelling evidence regarding the effectiveness and usefulness of game-based learning. Nevertheless, we are optimistic that this is an issue resolved in the future. So far, most of the evidence points in a positive direction. To conclude, the potential high effort to create good games for 
learning is best justified by its opportunities for learners that face problems in traditional educational settings or with respect to specific curricular topics.

We proposed a framework constituting three basic factors - cognition, emotion and sociality - that need to be kept in balance in order to exhaust these opportunities and create individually adaptive and effective learning environments. By mastering this learner-centred balancing act, game-based learning enables students to overcome learning obstacles or proceed in learning with more ease: (i) Games for learning provide different approaches for knowledge transfer and in general for access to knowledge, alternating the traditional "modus operandi" in formal teaching. (ii) Games can function as start-up support for a topic that may otherwise be a red rag to students. Future directions in game-based learning should also explore game-based learning as powerful way for inclusion and integration. With that in mind, when schools are again confronted with new pedagogical challenges and innovation pressure to meet the raising demands of society, game-based learning may be one piece of the puzzle. 


\section{Funding}

The current research was funded by the Leibniz-WissenschaftsCampus "Cognitive Interfaces" (MWK-WCT TP12; Simon Greipl and Manuel Ninaus) as well as the Leibniz-Competition Fund (SAW-2016-IWM-3; Manuel Ninaus).

\section{References}

Abt, C. C. (1970) Serious games. New York: Viking Press.

Ahmed, W. et al. (2010) 'Students' daily emotions in the classroom: Intra-individual variability and appraisal correlates', British Journal of Educational Psychology, 80(4), pp. 583-597. doi: 10.1348/000709910X498544.

All, A., Nuñez Castellar, E. P. and Van Looy, J. (2016) 'Assessing the effectiveness of digital game-based learning: Best practices’, Computers \& Education, 92-93, pp. 90-103. doi: 10.1016/j.compedu.2015.10.007.

Allsop, Y. and Jessel, J. (2018) 'Teachers' Experience and Reflections on Game-Based Learning in the Primary Classroom: Views from England and Italy', in Gamification in Education: Breakthroughs in Research and Practice. IGI Global, pp. 304-322.

Backlund, P. and Hendrix, M. (2013) 'Educational games - Are they worth the effort? A literature survey of the effectiveness of serious games', in. IEEE, pp. 1-8. doi: 10.1109/VSGAMES.2013.6624226.

Bandura, A. (2002) 'Social Cognitive Theory in Cultural Context', Applied Psychology, 51(2), pp. 269-290. doi: 10.1111/1464-0597.00092.

Barab, S. A., Ingram-Goble, A. and Warren, S. (2009) 'Conceptual play spaces', in Handbook of research on effective electronic gaming in education. IGI Global, pp. 989-1009.

Bavelier, D. et al. (2012) 'Brain Plasticity Through the Life Span: Learning to Learn and Action Video Games', Annual Review of Neuroscience, 35(1), pp. 391-416. doi: 10.1146/annurevneuro-060909-152832.

Becker, K. (2017a) Choosing and Using Digital Games in the Classroom. Cham: Springer International Publishing. doi: 10.1007/978-3-319-12223-6.

Becker, K. (2017b) 'Game-Based Lessons', in Becker, K., Choosing and Using Digital Games in the Classroom. Cham: Springer International Publishing, pp. 243-299. doi: 10.1007/978-3319-12223-6_9.

Binkley, M. et al. (2012) 'Defining Twenty-First Century Skills', in Griffin, P., McGaw, B., and Care, E. (eds) Assessment and Teaching of 21st Century Skills. Dordrecht: Springer Netherlands, pp. 17-66. doi: 10.1007/978-94-007-2324-5_2.

Boot, W. R. et al. (2008) 'The effects of video game playing on attention, memory, and executive control', Acta Psychologica, 129(3), pp. 387-398. doi:

10.1016/j.actpsy.2008.09.005. 
Bourgonjon, J. et al. (2010) 'Students' perceptions about the use of video games in the classroom', Computers \& Education, 54(4), pp. 1145-1156. doi: 10.1016/j.compedu.2009.10.022.

Boyle, E. A. et al. (2016) 'An update to the systematic literature review of empirical evidence of the impacts and outcomes of computer games and serious games', Computers \& Education, 94, pp. 178-192.

Bredl, K. and Bösche, W. (2013) Serious games and virtual worlds in education, professional development, and healthcare. IGI Global.

Breuer, J. (2017) 'Non vitae, sed ludo discimus? Grenzen des Lernens mit Computerspielen', in Zielinski, W. et al., Spielend lernen! Computerspiele(n) in Schule und Unterricht. München: kopaed (Schriftenreihe zur digitalen Gesellschaft NRW 5), pp. 17-26.

Bulger, M. E., Mayer, R. E. and Metzger, M. J. (2014) 'Knowledge and processes that predict proficiency in digital literacy', Reading and Writing, 27(9), pp. 1567-1583. doi: $10.1007 / \mathrm{s} 11145-014-9507-2$.

Burguillo, J. C. (2010) 'Using game theory and Competition-based Learning to stimulate student motivation and performance', Computers \& Education, 55(2), pp. 566-575. doi: 10.1016/j.compedu.2010.02.018.

Cagiltay, N. E., Ozcelik, E. and Ozcelik, N. S. (2015) 'The effect of competition on learning in games’, Computers \& Education, 87, pp. 35-41. doi: 10.1016/j.compedu.2015.04.001.

Chen, C.-H. and Law, V. (2016) 'Scaffolding individual and collaborative game-based learning in learning performance and intrinsic motivation', Computers in Human Behavior, 55, pp. 1201-1212. doi: 10.1016/j.chb.2015.03.010.

Chow, A. F., Woodford, K. C. and Maes, J. (2011) 'Deal or No Deal: using games to improve student learning, retention and decision-making', International Journal of Mathematical Education in Science and Technology, 42(2), pp. 259-264. doi: 10.1080/0020739X.2010.519796.

Connolly, T. M. et al. (2012) 'A systematic literature review of empirical evidence on computer games and serious games', Computers \& Education, 59(2), pp. 661-686. doi: 10.1016/j.compedu.2012.03.004.

Craig, S. et al. (2004) 'Affect and learning: An exploratory look into the role of affect in learning with AutoTutor', Journal of Educational Media, 29(3), pp. 241-250. doi: $10.1080 / 1358165042000283101$.

Crocco, F., Offenholley, K. and Hernandez, C. (2016) 'A Proof-of-Concept Study of GameBased Learning in Higher Education', Simulation \& Gaming, 47(4), pp. 403-422. doi: $10.1177 / 1046878116632484$.

Csikszentmihalyi, M. (1990) The psychology of optimal experience New York. Harper \& Row.

Daschmann, E. C., Goetz, T. and Stupnisky, R. H. (2011) 'Testing the predictors of boredom at school: Development and validation of the precursors to boredom scales: Antecedents to boredom scales', British Journal of Educational Psychology, 81(3), pp. 421-440. doi: 10.1348/000709910X526038. 
Delacruz, G. C., Chung, G. K. W. K. and Baker, E. L. (2010) 'Validity Evidence for Games as Assessment Environments: (642152011-001)'. American Psychological Association. doi: 10.1037/e642152011-001.

Deterding, S. (2014) 'Gamification Absolved?', Gamification Research Network, 5 August. Available at: http://gamification-research.org/2014/08/gamification-absolved-2/ (Accessed: 16 April 2018).

Djaouti, D. et al. (2011) 'Origins of Serious Games', in Ma, M., Oikonomou, A., and Jain, L. C. (eds) Serious Games and Edutainment Applications. London: Springer London, pp. 25-43. doi: 10.1007/978-1-4471-2161-9 3.

D’Mello, S. and Graesser, A. (2014) 'Confusion and its dynamics during device comprehension with breakdown scenarios', Acta Psychologica, 151, pp. 106-116. doi: 10.1016/j.actpsy.2014.06.005.

Dondlinger, M. J. (2007) 'Educational Video Game Design: A Review of the Literature', 4(1), p. 11.

Dow, D. N. (2013) 'Historical veneers anachronism, simulation, and art history in Assassin's Creed II', Playing with the past: Digital games and the simulation of history, 215.

Drachsler, H. and Greller, W. (2016) 'Privacy and Learning Analytics-it's a DELICATE issue', Proceedings of $L A K, 16, \mathrm{p} .10$.

Echao, O. F. S. and Romero, M. (2017) 'Creative and Collaborative Problem Solving Development Through Serious Games Co-Creation', in European Conference on Games Based Learning. Academic Conferences International Limited, pp. 793-797.

Engeser, S. and Rheinberg, F. (2008) 'Flow, performance and moderators of challenge-skill balance', Motivation and Emotion, 32(3), pp. 158-172. doi: 10.1007/s11031-008-9102-4.

ESA (2017) The Entertainment Software Association. Available at:

http://www.theesa.com/about-esa/essential-facts-computer-video-game-industry/ (Accessed: 19 April 2018).

Gabbiadini, A. and Greitemeyer, T. (2017) 'Uncovering the association between strategy video games and self-regulation: A correlational study', Personality and Individual Differences, 104, pp. 129-136. doi: 10.1016/j.paid.2016.07.041.

Gee, J. P. (2003) What video games have to teach us about learning and literacy. 1st ed. New York: Palgrave Macmillan.

Giannakas, F. et al. (2018) 'A critical review of 13 years of mobile game-based learning', Educational Technology Research and Development, 66(2), pp. 341-384. doi: 10.1007/s11423-017-9552-z.

Gomoll, A. H. et al. (2007) 'Surgical Experience Correlates with Performance on a Virtual Reality Simulator for Shoulder Arthroscopy', The American Journal of Sports Medicine, 35(6), pp. 883-888. doi: 10.1177/0363546506296521.

Green, C. S. and Bavelier, D. (2012) 'Learning, Attentional Control, and Action Video Games', Current Biology, 22(6), pp. R197-R206. doi: 10.1016/j.cub.2012.02.012. 
Greipl, S. et al. (2019) 'A Fun-Accuracy Trade-Off in Game-Based Learning', in Gentile, M., Allegra, M., and Söbke, H. (eds) Games and Learning Alliance. Springer International Publishing (Lecture Notes in Computer Science), pp. 167-177.

Hainey, T. et al. (2016) 'A systematic literature review of games-based learning empirical evidence in primary education', Computers \& Education, 102, pp. 202-223. doi: 10.1016/j.compedu.2016.09.001.

Hämäläinen, R. and Oksanen, K. (2012) 'Challenge of supporting vocational learning: Empowering collaboration in a scripted 3D game - How does teachers' real-time orchestration make a difference?', Computers \& Education, 59(2), pp. 281-293. doi: 10.1016/j.compedu.2012.01.002.

Hamari, J., Koivisto, J. and Sarsa, H. (2014) 'Does Gamification Work? -- A Literature Review of Empirical Studies on Gamification', in. IEEE, pp. 3025-3034. doi: 10.1109/HICSS.2014.377.

Harteveld, C. and Bekebrede, G. (2011) 'Learning in Single-Versus Multiplayer Games: The More the Merrier?', Simulation \& Gaming, 42(1), pp. 43-63. doi: $10.1177 / 1046878110378706$.

Heidig, S., Müller, J. and Reichelt, M. (2015) 'Emotional design in multimedia learning: Differentiation on relevant design features and their effects on emotions and learning', Computers in Human Behavior, 44, pp. 81-95. doi: 10.1016/j.chb.2014.11.009.

Hills, T. T., Todd, P. M. and Goldstone, R. L. (2008) 'Search in external and internal spaces: evidence for generalized cognitive search processes', Psychological Science, 19(8), pp. 802808. doi: 10.1111/j.1467-9280.2008.02160.x.

Hoffman, B. and Nadelson, L. (2010) 'Motivational engagement and video gaming: a mixed methods study', Educational Technology Research and Development, 58(3), pp. 245-270. doi: 10.1007/s11423-009-9134-9.

Holmes, E. A. et al. (2010) 'Key Steps in Developing a Cognitive Vaccine against Traumatic Flashbacks: Visuospatial Tetris versus Verbal Pub Quiz', PLoS ONE. Edited by K. Hashimoto, 5(11), p. e13706. doi: 10.1371/journal.pone.0013706.

Huizenga, J. C. et al. (2017) 'Teacher perceptions of the value of game-based learning in secondary education', Computers \& Education, 110, pp. 105-115. doi: 10.1016/j.compedu.2017.03.008.

Illeris, K. (2007) How we learn: learning and non-learning in school and beyond. English ed. London; New York: Routledge.

Insider, B. G., Business (2019) How big is 'Fortnite'? With nearly 250 million players, it's over two-thirds the size of the US population, Business Insider Deutschland. Available at: https://www.businessinsider.de/how-many-people-play-fortnite-2018-11 (Accessed: 29 May 2019).

Izard, C. E. (2009) 'Emotion Theory and Research: Highlights, Unanswered Questions, and Emerging Issues', Annual Review of Psychology, 60(1), pp. 1-25. doi: 10.1146/annurev.psych.60.110707.163539.

Jarvis, P. (1992) Paradoxes of learning: on becoming an individual in society. 1st ed. San Francisco: Jossey-Bass (The Jossey-Bass higher and adult education series). 
Johnson, D. W. and Johnson, R. T. (1996) 'Cooperation and the use of technology', Handbook of research for educational communications and technology: A project of the Association for Educational Communications and Technology, pp. 1017-1044.

Kafai, Y. B. and Burke, Q. (2015) 'Constructionist Gaming: Understanding the Benefits of Making Games for Learning', Educational Psychologist, 50(4), pp. 313-334. doi: 10.1080/00461520.2015.1124022.

Kao, G. Y.-M., Chiang, C.-H. and Sun, C.-T. (2017) 'Customizing scaffolds for game-based learning in physics: Impacts on knowledge acquisition and game design creativity', Computers \& Education, 113, pp. 294-312. doi: 10.1016/j.compedu.2017.05.022.

Kapp, K. M. (2012) The gamification of learning and instruction: game-based methods and strategies for training and education. San Francisco, CA: Pfeiffer.

Kapur, M. (2008) 'Productive Failure', Cognition and Instruction, 26(3), pp. 379-424. doi: $10.1080 / 07370000802212669$.

Kapur, M. and Bielaczyc, K. (2012) 'Designing for Productive Failure', Journal of the Learning Sciences, 21(1), pp. 45-83. doi: 10.1080/10508406.2011.591717.

Ke, F. and Grabowski, B. (2007) 'Gameplaying for maths learning: cooperative or not?', British Journal of Educational Technology, 38(2), pp. 249-259. doi: 10.1111/j.14678535.2006.00593.x.

Kennedy-Clark, S. and Thompson, K. (2011) 'What Do Students Learn When Collaboratively Using A Computer Game in the Study of Historical Disease Epidemics, and Why?', Games and Culture, 6(6), pp. 513-537. doi: 10.1177/1555412011431361.

Kiili, K. et al. (2014) 'Flow framework for analyzing the quality of educational games', Entertainment Computing, 5(4), pp. 367-377. doi: 10.1016/j.entcom.2014.08.002.

Kiili, K. et al. (2018) 'Exploring the Educational Potential of a Game-Based Math Competition':, International Journal of Game-Based Learning, 8(2), pp. 14-28. doi: 10.4018/IJGBL.2018040102.

Kiili, K. and Ketamo, H. (2017) 'Evaluating Cognitive and Affective Outcomes of a Digital Game-Based Math Test', IEEE Transactions on Learning Technologies, pp. 1-1. doi: 10.1109/TLT.2017.2687458.

Kiili, K., Moeller, K. and Ninaus, M. (2018) 'Evaluating the effectiveness of a game-based rational number training - In-game metrics as learning indicators', Computers \& Education, 120, pp. 13-28. doi: 10.1016/j.compedu.2018.01.012.

Kim, Y. J. and Shute, V. J. (2015) 'The interplay of game elements with psychometric qualities, learning, and enjoyment in game-based assessment', Computers \& Education, 87, pp. 340356. doi: 10.1016/j.compedu.2015.07.009.

Kirschner, P. A., Kirschner, F. and Paas, F. (2009) 'Cognitive load theory’.

Klopfer, E., Osterweil, S. and Salen, K. (2009) 'Moving learning games forward', Cambridge, MA: The Education Arcade. 
Klopfer, E. and Squire, K. (2008) 'Environmental Detectives - the development of an augmented reality platform for environmental simulations', Educational Technology Research and Development, 56(2), pp. 203-228. doi: 10.1007/s11423-007-9037-6.

Krannich, M. et al. (2019) 'Being over- or underchallenged in class: Effects on students' career aspirations via academic self-concept and boredom', Learning and Individual Differences, 69, pp. 206-218. doi: 10.1016/j.lindif.2018.10.004.

Krouse, R. Z. et al. (2011) 'Motivation, goal orientation, coaching, and training habits of women ultrarunners', Journal of Strength and Conditioning Research, 25(10), pp. 2835-2842. doi: 10.1519/JSC.0b013e318204caa0.

Lave, J. and Wenger, E. (1991) Situated learning: legitimate peripheral participation. Cambridge [England]; New York: Cambridge University Press (Learning in doing).

Lenhart, A. et al. (2008) 'Teens' gaming experiences are diverse and include significant social interaction and civic engagement', p. 76.

Li, M.-C. and Tsai, C.-C. (2013) 'Game-Based Learning in Science Education: A Review of Relevant Research', Journal of Science Education and Technology, 22(6), pp. 877-898. doi: 10.1007/s10956-013-9436-x.

Lumsden, J. et al. (2016) 'Gamification of Cognitive Assessment and Cognitive Training: A Systematic Review of Applications and Efficacy', JMIR Serious Games, 4(2). doi: 10.2196/games.5888.

Margaryan, A., Littlejohn, A. and Vojt, G. (2011) 'Are digital natives a myth or reality? University students' use of digital technologies', Computers \& Education, 56(2), pp. 429-440. doi: 10.1016/j.compedu.2010.09.004.

Moore, D. A. and Tenney, E. R. (2012) 'Time Pressure, Performance, and Productivity', in Neale, M. A. and Mannix, E. A. (eds) Research on Managing Groups and Teams. Emerald Group Publishing Limited, pp. 305-326. doi: 10.1108/S1534-0856(2012)0000015015.

Moreno, R. (2006) 'Does the modality principle hold for different media? A test of the methodaffects-learning hypothesis: Modality principle', Journal of Computer Assisted Learning, 22(3), pp. 149-158. doi: 10.1111/j.1365-2729.2006.00170.x.

Moyles, J. R. (1989) Just playing? the role and status of play in early childhood education. Milton Keynes [England] ; Philadelphia: Open University Press.

Nacke, L. E. and Deterding, S. (2017) 'The maturing of gamification research', Computers in Human Behavior, 71, pp. 450-454. doi: 10.1016/j.chb.2016.11.062.

Nebel, S., Schneider, S. and Rey, G. D. (2016) 'Mining Learning and Crafting Scientific Experiments: A Literature Review on the Use of Minecraft in Education and Research', Journal of Educational Technology \& Society, 19(2), pp. 355-366. Available at: http://www.jstor.org/stable/jeductechsoci.19.2.355 (Accessed: 10 April 2018).

Nicholson, S. (2013) 'Exploring gamification techniques for classroom management', Games+ Learning+ Society, 9, pp. 21-27.

Nielson, K. A. and Powless, M. (2007) 'Positive and negative sources of emotional arousal enhance long-term word-list retention when induced as long as 30min after learning', Neurobiology of Learning and Memory, 88(1), pp. 40-47. doi: 10.1016/j.nlm.2007.03.005. 
Ninaus, M., Moeller, K., et al. (2017) 'Acceptance of Game-Based Learning and Intrinsic Motivation as Predictors for Learning Success and Flow Experience', International Journal of Serious Games, 4(3). doi: 10.17083/ijsg.v4i3.176.

Ninaus, M., Kiili, K., et al. (2017) 'Assessing fraction knowledge by a digital game', Computers in Human Behavior, 70, pp. 197-206. doi: 10.1016/j.chb.2017.01.004.

Nishikawa, K. A. and Jaeger, J. (2011) 'A Computer Simulation Comparing the Incentive Structures of Dictatorships and Democracies', Journal of Political Science Education, 7(2), pp. 135-142.

Park, Y. (2011) 'A pedagogical framework for mobile learning: Categorizing educational applications of mobile technologies into four types', The International Review of Research in Open and Distributed Learning, 12(2), pp. 78-102. Available at:

http://www.irrodl.org/index.php/irrodl/article/view/791 (Accessed: 17 April 2018).

Peckham, M. (2013) 'The Inexorable Decline of World of Warcraft', Time. Available at: http://techland.time.com/2013/05/09/the-inexorable-decline-of-world-of-warcraft/ (Accessed: 29 May 2019).

Pekrun, R. et al. (2014) 'Boredom and academic achievement: Testing a model of reciprocal causation.', Journal of Educational Psychology, 106(3), pp. 696-710. doi: 10.1037/a0036006.

Perrotta, C. et al. (2013) 'Game-based learning: Latest evidence and future directions', Slough: NFER.

Petralito, S. et al. (2017) 'A Good Reason to Die: How Avatar Death and High Challenges Enable Positive Experiences’, in. ACM Press, pp. 5087-5097. doi: 10.1145/3025453.3026047.

Pittman, C. (2013) 'Teaching with portals: The intersection of video games and physics education', LEARNing Landscapes, 6(2), pp. 341-360.

Plass, J. L., Homer, B. D., et al. (2013) 'Metrics in Simulations and Games for Learning', in Seif El-Nasr, M., Drachen, A., and Canossa, A. (eds) Game Analytics. London: Springer London, pp. 697-729. doi: 10.1007/978-1-4471-4769-5_31.

Plass, J. L., O'Keefe, P. A., et al. (2013) 'The impact of individual, competitive, and collaborative mathematics game play on learning, performance, and motivation.', Journal of Educational Psychology, 105(4), pp. 1050-1066. doi: 10.1037/a0032688.

Plass, J. L., Homer, B. D. and Kinzer, C. K. (2015) 'Foundations of Game-Based Learning', Educational Psychologist, 50(4), pp. 258-283. doi: 10.1080/00461520.2015.1122533.

Plass, J. L. and Kaplan, U. (2016) 'Emotional Design in Digital Media for Learning', in Emotions, Technology, Design, and Learning. Elsevier, pp. 131-161. doi: 10.1016/B978-0-12801856-9.00007-4.

Pohl, M., Rester, M. and Judmaier, P. (2009) 'Interactive Game Based Learning: Advantages and Disadvantages', in Stephanidis, C. (ed.) Universal Access in Human-Computer Interaction. Applications and Services. Berlin, Heidelberg: Springer Berlin Heidelberg, pp. 92-101. doi: 10.1007/978-3-642-02713-0_10.

Prensky, M. (2007) Digital game-based learning. St. Paul, MN: Paragon House. 
Qian, M. and Clark, K. R. (2016) 'Game-based Learning and 21st century skills: A review of recent research', Computers in Human Behavior, 63, pp. 50-58. doi: 10.1016/j.chb.2016.05.023.

Rebolledo, B. J. et al. (2015) 'Arthroscopy Skills Development With a Surgical Simulator: A Comparative Study in Orthopaedic Surgery Residents', The American Journal of Sports Medicine, 43(6), pp. 1526-1529. doi: 10.1177/0363546515574064.

Rey, G. D. (2012) 'A review of research and a meta-analysis of the seductive detail effect', Educational Research Review, 7(3), pp. 216-237. doi: 10.1016/j.edurev.2012.05.003.

Ritterfeld, U., Cody, M. J. and Vorderer, P. (eds) (2009) Serious games: mechanisms and effects. New York: Routledge.

Ruggiero, D. (2013) 'Video games in the classroom: The teacher point of view', in Games for Learning workshop of the Foundations of Digital Games conference, Chania, Greece.

Rüst, C. A. et al. (2012) 'Participation and Performance Trends in Triple Iron Ultra-triathlon - a Cross-sectional and Longitudinal Data Analysis', Asian Journal of Sports Medicine, 3(3). doi: 10.5812/asjsm.34605.

Ryan, R. M. and Deci, E. L. (2000) 'Self-determination theory and the facilitation of intrinsic motivation, social development, and well-being.', American Psychologist, 55(1), pp. 68-78. doi: 10.1037/0003-066X.55.1.68.

Ryan, R. M., Rigby, C. S. and Przybylski, A. (2006) 'The Motivational Pull of Video Games: A Self-Determination Theory Approach', Motivation and Emotion, 30(4), pp. 344-360. doi: 10.1007/s11031-006-9051-8.

Sanchez, C. A. and Wiley, J. (2006) 'An examination of the seductive details effect in terms of working memory capacity', Memory \& Cognition, 34(2), pp. 344-355. doi: 10.3758/BF03193412.

Sanchez, E. (2017) 'Competition and Collaboration for Game-Based Learning: A Case Study', in Wouters, P. and van Oostendorp, H. (eds) Instructional Techniques to Facilitate Learning and Motivation of Serious Games. Cham: Springer International Publishing, pp. 161-184. doi: 10.1007/978-3-319-39298-1_9.

Schell, J. (2015) The art of game design: a book of lenses. Second edition. Boca Raton: CRC Press.

Schifter, C. (2013) 'Minecraft as a teaching tool: One case study', in. Society for Information Technology \& Teacher Education International Conference, Association for the Advancement of Computing in Education (AACE), pp. 2951-2955. Available at: https://www.learntechlib.org/p/48540/ (Accessed: 10 April 2018).

Shute, V. J. and Ke, F. (2012) 'Games, Learning, and Assessment', in Ifenthaler, D., Eseryel, D., and Ge, X. (eds) Assessment in Game-Based Learning. New York, NY: Springer New York, pp. 43-58. doi: 10.1007/978-1-4614-3546-4_4.

Shute, V. J., Ke, F. and Wang, L. (2017) 'Assessment and Adaptation in Games', in Wouters, P. and van Oostendorp, H. (eds) Instructional Techniques to Facilitate Learning and Motivation of Serious Games. Cham: Springer International Publishing, pp. 59-78. doi: 10.1007/978-3319-39298-1_4. 
Shute, V. J. and Moore, G. R. (2017) 'Consistency and validity in game-based stealth assessment', Technology enhanced innovative assessment: Development, modeling, and scoring from an interdisciplinary perspective, pp. 31-51.

Shute, V. J. and Ventura, M. (2013) Stealth assessment: measuring and supporting learning in video games. Cambridge, Massachusetts: The MIT Press (The John D. and Catherine T. Macarthur Foundation reports on digital media and learning).

Sliney, A. and Murphy, D. (2011) 'Using Serious Games for Assessment', in Ma, M., Oikonomou, A., and Jain, L. C. (eds) Serious Games and Edutainment Applications. London: Springer London, pp. 225-243. doi: 10.1007/978-1-4471-2161-9_12.

Snow, B. (2016) The Potential for Game-based Learning to Improve Outcomes for Nontraditional Students. Retrieved from Muzzy Lane Software website: http://www. muzzylane. com/wpcontent/uploads/MuzzyLaneResearchReport-1. pdf.

Squire, K. D. (2004) Replaying History: Learning World History Through Playing Civilization III. Indiana University. Available at: https://books.google.de/books?id=I6d7NwAACAAJ.

Suh, S., Kim, S. W. and Kim, N. J. (2010) 'Effectiveness of MMORPG-based instruction in elementary English education in Korea: Effectiveness of MMORPG-based instruction', Journal of Computer Assisted Learning, 26(5), pp. 370-378. doi: 10.1111/j.13652729.2010.00353.x.

Tahir, R. and Wang, A. I. (2017) 'State of the art in Game Based Learning: Dimensions for Evaluating Educational Games', in European Conference on Games Based Learning. Academic Conferences International Limited, pp. 641-650.

Tajfel, H. and Turner, J. C. (1979) 'An integrative theory of intergroup conflict', The social psychology of intergroup relations, 33(47), p. 74.

Tondello, G. F. et al. (2016) 'The Gamification User Types Hexad Scale', in Proceedings of the 2016 Annual Symposium on Computer-Human Interaction in Play - CHI PLAY'16. the 2016 Annual Symposium, Austin, Texas, USA: ACM Press, pp. 229-243. doi: 10.1145/2967934.2968082.

Um, E. "Rachel” et al. (2012) 'Emotional design in multimedia learning.', Journal of Educational Psychology, 104(2), pp. 485-498. doi: 10.1037/a0026609.

ter Vrugte, J. et al. (2015) 'How competition and heterogeneous collaboration interact in prevocational game-based mathematics education', Computers \& Education, 89, pp. 42-52. doi: 10.1016/j.compedu.2015.08.010.

Vygotsky, L. S. (1980) Mind in society: The development of higher psychological processes. Harvard university press.

Walldén, S. and Soronen, A. (2004) 'From Television and Computers to Digital Television', p. 72 .

Watson, W. and Yang, S. (2016) 'Games in schools: Teachers' perceptions of barriers to gamebased learning', Journal Of Interactive Learning Research, 27(2), pp. 153-170.

Wenger, E. (2008) Communities of practice: learning, meaning, and identity. Cambridge: Cambridge Univ. Press (Learning in doing : social, cognitive, and computational perspectives). 
Wilkinson, P. (2013) 'Affective educational games: Utilizing emotions in game-based learning', in 2013 5th International Conference on Games and Virtual Worlds for Serious Applications (VS-GAMES), pp. 1-8. doi: 10.1109/VS-GAMES.2013.6624219.

Wilkinson, P. (2016) 'A Brief History of Serious Games', in Entertainment Computing and Serious Games. Springer, Cham (Lecture Notes in Computer Science), pp. 17-41. doi: 10.1007/978-3-319-46152-6_2.

Wouters, P. et al. (2013) 'A meta-analysis of the cognitive and motivational effects of serious games.', Journal of Educational Psychology, 105(2), pp. 249-265. doi: 10.1037/a0031311.

Yang, Y.-T. C. (2012) 'Building virtual cities, inspiring intelligent citizens: Digital games for developing students' problem solving and learning motivation', Computers \& Education, 59(2), pp. 365-377. doi: 10.1016/j.compedu.2012.01.012.

Yang, Y.-T. C., Lin, M. Y. D. and Chen, S. Y. (2018) 'Effects of anxiety levels on learning performance and gaming performance in digital game-based learning', Journal of Computer Assisted Learning. doi: $10.1111 /$ jcal.12245.

Yerkes, R. M. and Dodson, J. D. (1908) 'The relation of strength of stimulus to rapidity of habit-formation', Journal of Comparative Neurology and Psychology, 18(5), pp. 459-482. doi: 10.1002/cne.920180503. 